\title{
Het Cultureel Interview als hulpmiddel voor cultuursensi- tieve zorg in de huisartsenpraktijk
}

\section{Onderzoek naar effecten en eerste ervaringen van patiënten en poh's-ggz}

\author{
Michelle Hendriks · Karen Hosper · Koos Bartels · Richard Starmans · Anneke van Schaik · Walter Devillé
}

Published online: 4 April 2020

(C) The Author(s) 2020

\section{Samenvatting}

Doel Het diagnosticeren en behandelen van psychische klachten bij niet-westerse migranten in de huisartsenpraktijk blijkt moeilijk. Het Brief Cultural Interview (BCI) kan helpen bij het inzicht verkrijgen in relevante culturele factoren. We onderzochten de effecten van en ervaringen met het BCI toegepast door praktijkondersteuners-geestelijke gezondheidszorg (poh'sggz).

Methode Geclusterd effectonderzoek onder niet-westerse migranten die met psychische klachten bij de huisarts kwamen. In de interventiegroep zaten elf poh's; vijf poh's-ggz gaven gebruikelijke zorg. Patiënten beantwoordden bij de start van de behandeling en vier maanden later vragen over vertrouwen in de zorg, waardering van de patiënt-poh-relatie, gevoel van controle, en psychische en fysieke gezondheid. We verzamelden kwalitatieve data over de ervaringen van de poh's-ggz en patiënten met het BCI.

\section{Hendriks $\cdot$ W. Devillé $(\bowtie)$}

NIVEL, Utrecht, Nederland

w.deville@xs4all.nl

\section{K. Hosper}

Pharos, Utrecht, Nederland

K. Bartels

Zorggroep Almere, Almere, Nederland

\section{R. Starmans}

Stichting Haagse Gezondheidscentra, Den Haag, Nederland

A. van Schaik

GGZ inGeest, Amsterdam, Nederland

\section{W. Devillé}

Julius Centrum voor Gezondheidswetenschappen en Eerstelijnsgeneeskunde, Universitair Medisch Centrum Utrecht, Utrecht, Nederland
Resultaten In totaal werden 87 patiënten geïncludeerd. In de interventiegroep namen 31 patiënten deel aan de voor- en nameting, en in de controlegroep vijftien. De verschilscores op de uitkomstmaten verschilden niet significant tussen beide groepen. Zeven van de elf poh's-ggz uit de interventiegroep hebben patiënten geïncludeerd. De geïnterviewde acht poh's-ggz en negen patiënten waren positief over de meerwaarde van het BCI.

Conclusie Het onderzoek heeft beperkte kennis opgeleverd over het gebruik van het BCI door de poh's-ggz. Het BCI kan worden ingezet voor het bevorderen van cultuursensitief handelen, maar is moeilijker toepasbaar dan gedacht. Verder onderzoek is nodig naar de effecten van het BCI en de implementeerbaarheid in de huisartsenpraktijk.

Trefwoorden cultuursensitieve zorg · ggz • praktijkondersteuner $\cdot$ huisarts

Cultural interview as tool for providing culturally sensitive care in general practice

Study on the effects and experiences of patients and mental health nurses

\footnotetext{
Abstract

Aim Diagnosing and treating mental health problems in non-western migrants visiting general practice appears difficult. The Brief Cultural Interview (BCI) can help by providing insight into relevant cultural factors. We examined the effects of and experiences with the BCI as implemented by mental health nurses in general practice.

Methods Clustered effect study among non-western migrants who visited their general practitioner with mental health problems. Eleven mental health nurses were trained to conduct the BCI and five mental health nurses provided care as usual. At the start of
} 
treatment and four months later, patients answered questions on trust in health care, the patient-nurse relationship, self-control, physical and mental health. We collected qualitative data on the experiences of mental health nurses and patients with the BCI.

Results In total 84 patients were included. In the intervention group 31 patients participated at baseline and follow-up, in the control group 15. Seven out of eleven trained nurses included patients. Change scores on the outcomes did not differ significantly between groups. The eight mental health nurses and nine patients interviewed were positive about the usefulness of the BCI.

Conclusion The study has to a limited extent added to our knowledge on the BCI implemented by mental health nurses. The BCI can be used to enhance culturally sensitive care, but is not easy to implement in daily care. Future research is needed on the effects of the BCI and the ease of implementation in general practice.

Keywords Cultural Formulation · culturally sensitive care $\cdot$ mental health $\cdot$ general practitioner

\section{Inleiding}

Psychische klachten en somatisch onvoldoende verklaarde lichamelijke klachten (SOLK) komen vaker voor bij niet-westerse migranten dan bij autochtonen $[1,2]$. Het blijkt echter moeilijk om bij deze groep de juiste diagnose te stellen en een passende behandeling te kiezen. Effectieve behandelvormen bereiken patiënten met een migrantenachtergrond onvoldoende [3]. Dit komt mogelijk doordat patiënt en arts verschillende visies op ziekte en gezondheid hebben. Etnische en socio-economische groepen verschillen in hun gebruik en houding ten opzichte van de geestelijke gezondheidszorg [4-7].

De etnische diversiteit van de huidige patiëntenpopulatie vraagt om een cultuursensitieve aanpak. Aandacht voor de sociale en culturele context leidt tot een betere arts-patiëntrelatie en effectievere behandeling [8-10]. Dit is al langer bekend in de psychiatrie, waar in de DSM-IV (2000) een Outline of Cultural Formulation (OCF) is opgenomen. De OCF was bedoeld als hulpmiddel bij het achterhalen van culturele en contextuele factoren die relevant zijn bij het stellen van de diagnose en het opstellen van het behandelplan [11, 12]. Het was echter niet duidelijk wanneer de OCF het beste kon worden gebruikt, voor welke patiënten, op welk moment in de zorg en met welk doel [13].

Om het vragen naar culturele en contextuele factoren te bevorderen, zijn internationaal verschillende interviewleidraden opgesteld. Een voorbeeld hiervan is het Cultural Formulation Interview, dat is opgenomen in de DMS-5. In Nederland is het zogenaamde Cultureel Interview ontwikkeld [14, 15], dat oorspronkelijk uit 48 vragen bestond. In 2006 is er een verkorte versie van 24 vragen ontwikkeld, het Brief Cultural In- terview (BCI) [11, 16]. Eerdere onderzoeken lieten de volgende positieve effecten zien: een empowerend effect bij de patiënt, meer inzicht in de patiënt, diens gedrag en visie op de klachten, meer informatie die relevant is voor het opstellen van het behandelplan, een verbeterde arts-patiëntrelatie en grotere tevredenheid bij de patiënt $[15,17,18]$.

Hoewel mensen met psychische klachten in Nederland eerst naar de huisarts gaan, is het BCI tot nu toe niet toegepast in de huisartsenpraktijk. In dit onderzoek werden de volgende vragen beantwoord:

1. Op welke punten moet het BCI aangepast worden om toegepast te kunnen worden door de praktijkondersteuners-geestelijke gezondheidszorg (poh'sggz) in de huisartsenpraktijk?

2. Hoe ervaren de poh's-ggz en patiënten de toepassing van het $\mathrm{BCI}$ ?

3. Heeft het BCI positieve effecten voor de patiënt?

\section{Methode}

\section{Onderzoeksopzet}

Van november 2013 tot januari 2015 voerden we een geclusterd effectonderzoek uit onder niet-westerse migranten die met psychische klachten bij de huisarts kwamen. Poh's-ggz namen het BCI af onder nieuwe patiënten. We vergeleken deze patiënten met patiënten die gebruikelijke zorg kregen (controlegroep). Beide groepen beantwoordden binnen twee weken na de intake (het startinterview) en ongeveer vier maanden na de start van de behandeling (het vervolginterview) vragen over hun vertrouwen in de zorg, waardering van de patiënt-poh-ggz-relatie, gevoel van controle en psychische en fysieke gezondheid. Daarnaast verzamelden we kwalitatieve data over de ervaringen van poh's-ggz en patiënten met het BCI. Beide groepen zijn hiervoor geïnterviewd.

Het onderzoek is voorgelegd aan de Medisch Ethische Toetsingscommissie van het Amsterdam UMC - locatie VUmc. Volgens de commissie viel het onderzoek niet onder de Wet Medisch Onderzoek. Het onderzoek is aangemeld bij het College bescherming persoonsgegevens (m1543065).

\section{Setting}

Vijftien huisartsenpraktijken uit wijken met een relatief hoog percentage migranten deden mee: vijf in Den Haag, acht in Almere en - na vaststelling van de lage instroom - twee in Utrecht. De deelnemende poh's-ggz in deze praktijken werden op basis van de eigen voorkeur en reeds aanwezige bekendheid met het Cultureel Interview toegewezen aan de interventie- of controlegroep. De interventiegroep bestond uit elf poh's-ggz die werkzaam waren in tien huisartsenpraktijken. Uitgevallen poh's-ggz werden vervangen door nieuw getrainde poh's. Uiteindelijk hebben zeven poh's-ggz patiënten geïncludeerd in het on- 
Box 1. Cultureel Interview zoals afgenomen door de poh's-ggz

Vragen tijdens intake

Culturele definities en verklaringen

Klachten en zorgen

1. Welke klachten of zorgen brengen u hier vandaag?

2. Waar maakt $\mathrm{u}$ zich het meeste zorgen over?

Woorden van de patiënt

3. Hoe zou u uw probleem vertellen en uitleggen aan anderen, bijvoorbeeld familie of vrienden?

4. Zijn er ook woorden of uitdrukkingen in uw eigen taal voor uw klachten/zorgen? Welke woorden en uitdrukkingen zijn dat?

Eigen verklaringen

5. Waarom overkomt $\mathrm{u}$ dit nu, denkt $\mathrm{u}$ ? Wat is volgens $\mathrm{u}$ de oorzaak van uw probleem?

6. Wat is volgens anderen in uw familie (of in uw omgeving) de oorzaak van uw probleem?

Hulpzoekgedrag

7. Bij wie zoekt u hulp voor uw klachten/zorgen? (Denk aan familie of vrienden, bij traditionele of alternatieve genezers, in Nederland of het buitenland). Is er iemand die u om hulp gevraagd heeft?

\section{Vragen tijdens tweede consult \\ Culturele identiteit}

Migratiegeschiedenis

1. Waar bent u geboren? Bent $\mathrm{u}$ daar ook opgegroeid?

2. Indien in Nederland geboren: waaraan merkt u dat uw ouders in ... geboren zijn en $\mathrm{u}$ in Nederland?

3. Indien in het buitenland geboren: hoe was dat toen $\mathrm{u}$ naar Nederland kwam? Hoe oud was $\mathrm{u}$ ? Met wie kwam $\mathrm{u}$ ? Wat herinnert $\mathrm{u}$ zich daarvan? Waarom kwam u naar Nederland?

Taal

5. Met welke taal bent u opgegroeid? Spreekt u ook nog andere talen?

6. Welke taal spreekt u thuis? (Met uw partner? Met uw kinderen? Met uw vrienden?)

7. Kunt $u$ in het Nederlands goed uitleggen wat $u$ bedoelt? Zo niet, wat is voor $u$ moeilijk om uit te leggen of te begrijpen? Wie vraagt u om hulp daarbij?

Etniciteit en cultuur

8. In (land van herkomst) leven verschillende bevolkingsgroepen. Hoort u bij een bepaalde groep? En uw partner en familie?

9. Heeft $u$ contact met mensen uit die groep? Is dat belangrijk voor $u$ ?

10. Wat vindt $u$ het meest belangrijk aan uw cultuur? (eetgewoonten, respect, familie, feestdagen, eer)

11. Voelt $\mathrm{u}$ zich thuis in Nederland? Heeft $\mathrm{u}$ Nederlandse vrienden of kennissen?

12. Heeft $\mathrm{u}$ zich in Nederland wel eens uitgesloten of gediscrimineerd gevoeld? Kunt $\mathrm{u}$ daar een voorbeeld van geven? Komt dat vaker voor? Hoe is dat voor $u$ ?

\section{Culturele factoren in de psychosociale omgeving}

Familie en sociaal netwerk

13. Wat is uw leef-/woonsituatie op dit moment?

14. Hoe is het contact met (de rest) van uw familie? Waar wonen zij?

15. Bij wie kunt $\mathrm{u}$ terecht met uw verhaal? Aan wie vraagt $\mathrm{u}$ hulp of advies?

Steun en stress

16. Wat maakt het makkelijker om met uw probleem om te gaan?

17. Is er iets wat uw probleem erger maakt, zoals problemen met geld of met familie?

Geloof

18. Bent u gelovig? En uw familie?

19. Haalt u steun uit uw geloof? Zijn er geloofszaken waar u moeite mee heeft?

\section{Culturele elementen tussen patiënt en hulpverlener}

Relatie hulpverlener - patiënt

20. Wat zijn uw ervaringen met Nederlandse hulpverleners? Wat vindt u ervan als uw hulpverlener een man/ vrouw is? Is de religieuze achtergrond belangrijk?

21. Hoe kunnen hulpverleners van het gezondheidscentrum $\mathrm{u}$ het beste helpen? 
derzoek. De controlegroep bestond uit vijf poh's-ggz werkzaam in vijf praktijken. Voor de training verschilden beide groepen niet in de mate van culturele competentie gemeten met de Culturele Competentielijst [19].

\section{Interventie}

\section{Aangepast $\mathrm{BCl}$}

Op basis van consensus onder experts en een pre-test door drie poh's-ggz, hebben we het BCI van Groen en collega's op een aantal punten aangepast [11]. Waar hun versie begint met vragen over de culturele identiteit stelden de poh's-ggz eerst de vragen over culturele verklaringen voor de ziekte en de eigen klachten. Dit sluit aan bij recente ontwikkelingen van het Cultural Formulation Interview [12]. Er is een vraag over ervaren discriminatie toegevoegd en de formulering van enkele vragen is vereenvoudigd. Het aangepaste BCI bestond uit 21 vragen (zie box 1). Om aan te sluiten bij het natuurlijk verloop van de gesprekken werd het BCI over twee gesprekken afgenomen. In het eerste gesprek ging de poh-ggz in op de ervaren klachten en de culturele verklaringen. In het tweede gesprek kwamen de andere onderdelen aan bod. De inleiding is ingekort en afgestemd op het gebruik in de eerste lijn.

\section{Training van poh's-ggz}

De poh's-ggz in de interventiegroep zijn getraind in het toepassen van het BCI. De training bestond uit twee bijeenkomsten waarin we de achtergronden van het BCI toelichtten en instructies gaven voor het gebruik en de verslaglegging ervan. De deelnemers voerden tussen de bijeenkomsten een oefenopdracht uit in de praktijk. Na drie en negen maanden vonden vervolgbijeenkomsten plaats waarin de deelnemers ervaringen met het BCI uitwisselden en mogelijkheden bespraken om de inclusie van patiënten te vergroten. De poh's-ggz in de controlegroep hebben de training na afloop van het onderzoek ontvangen.

\section{Werving van de patiënten}

De poh's-ggz wierven deelnemers onder nieuwe patiënten die de huisarts naar hen doorverwees. De inclusiecriteria waren:

1. leeftijd vanaf achttien jaar;

2. verwijzing naar poh-ggz vanwege angstklachten, depressieve klachten of SOLK;

3. eerste of tweede generatie niet-westerse migrant volgens de definitie van het CBS. In eerste instantie zijn alleen migranten met een Marokkaanse, Turkse, Surinaamse of Antilliaanse/Arubaanse achtergrond benaderd. Vanwege een lage inclusie zijn later ook migranten uit andere niet-westerse landen geïncludeerd.

De powercalculatie werd gebaseerd op de uitkomstmaat therapietrouw, gedefinieerd als de proportie pa- tiënten die het behandelingstraject niet binnen zes maanden voortijdig afbreekt. Uitgaande van een bestaande uitval van $46 \%$ (uit de literatuur) wilden we dit door de interventie met een derde terugbrengen. Gecorrigeerd voor het clustereffect kwamen we op 105 deelnemers per arm, op basis van een survival logrank-analyse. Patiënten ontvingen van hun huisarts en/of poh-ggz mondelinge en korte schriftelijke informatie over het onderzoek. De poh-ggz vroeg of de patiënt wilde meedoen. Bij toestemming nam een interviewer telefonisch contact op met de patiënt om een afspraak te maken voor het startinterview. Aan het begin van dit interview tekende de patiënt een informed consent-formulier.

\section{Kwantitatief onderzoek}

Tabel 1 geeft een overzicht van de meetinstrumenten. We berekenden de volgende scores:

Patiëntenkenmerken:

- mate van acculturatie: de Lowlands Acculturation Scale (LAS), die uit vijf schalen bestaat: Vaardigheden, Tradities, Sociale integratie, Waarden en normen, en Verlies. We berekenden voor iedere schaal de somscore. Hogere scores duiden op een lagere acculturatie, behalve bij Sociale integratie [20].

\section{Uitkomstmaten:}

- waardering van de patiënt-poh-ggz-relatie: na het hercoderen van negatief geformuleerde stellingen, berekenden we de somscore op de Helping Alliance Questionnaire (HAQ-II) [21, 22].

- vertrouwen in de zorg: dit werd gemeten met vier stellingen over artsen in het algemeen, die zijn afgeleid van het werk van Dugan en collega's [23]. We berekenden de gemiddelde score op de stellingen.

- gevoel van controle: we stelden vijf vragen uit de schaal van Pearlin en Schooler [24]. Twee vragen namen we niet mee omdat die in een eerder onderzoek slecht met de schaal correleerden [25]. Vervolgens berekenden we de somscore.

- zelfgerapporteerde gezondheid: de zelfgerapporteerde psychische en lichamelijke gezondheid hebben we gemeten met de 12-Item Short Form Survey (SF-12) [26]. We berekenden een score voor fysieke gezondheid en psychische gezondheid conform het SMILE-onderzoek in Maastricht. Beide scores konden variëren van 0-100.

Extern geworven interviewers $(n=10)$ namen de genoemde vragenlijsten af tijdens een gestructureerd interview. Het interview vond plaats bij de patiënt thuis of in de huisartsenpraktijk en stond los van afname van het BCI. De vragenlijsten waren beschikbaar in het Nederlands, Turks, Marokkaans-Arabisch en Berber. Naast Nederlands spraken verschillende interviewers Turks, Marokkaans-Arabisch of Berber. De interviewers kregen vooraf een training van een dagdeel, gevolgd door enkele terugkombijeenkomsten. 


\section{Wetenschappelijk artikel}

Tabel 1 Overzicht van de meetinstrumenten

\begin{tabular}{|c|c|c|c|c|c|c|}
\hline & Instrument/variabelen & Voorbeeldvraag & $\begin{array}{l}\text { Aantal } \\
\text { vragen }\end{array}$ & Antwoordcategorieën & $\begin{array}{l}\text { Start inter- } \\
\text { view }\end{array}$ & $\begin{array}{l}\text { Vervolg- } \\
\text { interview }\end{array}$ \\
\hline \multicolumn{7}{|c|}{ Patiëntkenmerken } \\
\hline $\begin{array}{l}\text { Demografische } \\
\text { kenmerken }\end{array}$ & $\begin{array}{l}\text { Geboortejaar, geslacht, geboorteland van } \\
\text { de patiënt en zijn/haar ouders, hoogst } \\
\text { voltooide opleiding, burgerlijke staat, } \\
\text { inkomstenbron, financiële situatie, werk- } \\
\text { situatie en religie }\end{array}$ & In welk land bent u geboren? & 11 & Varieert & $x$ & \\
\hline $\begin{array}{l}\text { Mate van } \\
\text { acculturatie }\end{array}$ & Lowlands Acculturation Scale & $\begin{array}{l}\text { Ik vind het belangrijk om } \\
\text { onze tradities aan mijn (toe- } \\
\text { komstige) kinderen door te } \\
\text { geven }\end{array}$ & 25 & $\begin{array}{l}\text { Helemaal niet van } \\
\text { toepassing (score 1) - } \\
\text { heel erg van toepassing } \\
\text { (score 6) }\end{array}$ & $x$ & \\
\hline \multicolumn{7}{|l|}{ Uitkomstmaten } \\
\hline $\begin{array}{l}\text { Waardering } \\
\text { patiënt-zorg- } \\
\text { verlenerrelatie }\end{array}$ & Helping Alliance Questionnaire-II [21] & $\begin{array}{l}\text { Ik voel me begrepen door } \\
\text { mijn praktijkondersteuner }\end{array}$ & 19 & $\begin{array}{l}\text { Erg mee oneens } \\
\text { (score 1) - erg mee } \\
\text { eens (score 6) }\end{array}$ & $\mathrm{x}$ & $\mathrm{x}$ \\
\hline $\begin{array}{l}\text { Vertrouwen in } \\
\text { de zorg }\end{array}$ & $\begin{array}{l}\text { Questionnaire for Dutch Health Care } \\
\text { Consumer Panel }\end{array}$ & $\begin{array}{l}\text { Artsen zijn extreem grondig } \\
\text { en zorgvuldig }\end{array}$ & 4 & $\begin{array}{l}\text { Geheel mee oneens } \\
\text { (score 1) - geheel mee } \\
\text { eens (score 5) }\end{array}$ & $\mathrm{x}$ & $x$ \\
\hline $\begin{array}{l}\text { Gevoel van } \\
\text { controle }\end{array}$ & Schaal van Pearlin en Schooler [24] & $\begin{array}{l}\text { Ik heb weinig controle over } \\
\text { de dingen die me overkomen }\end{array}$ & 5 & $\begin{array}{l}\text { Helemaal mee oneens } \\
\text { (score 1) - helemaal } \\
\text { mee eens (score 4) }\end{array}$ & $\mathrm{x}$ & $\mathrm{x}$ \\
\hline $\begin{array}{l}\text { Psychische } \\
\text { gezondheid }\end{array}$ & SF-12 [26] & $\begin{array}{l}\text { Heeft u door een emotioneel } \\
\text { probleem in de afgelopen } \\
\text { vier weken minder bereikt } \\
\text { dan u zou willen? }\end{array}$ & 6 & Varieert & $x$ & $x$ \\
\hline $\begin{array}{l}\text { Fysieke ge- } \\
\text { zondheid }\end{array}$ & SF-12 [26] & $\begin{array}{l}\text { Wilt u aangeven in welke } \\
\text { mate u door uw gezond- } \\
\text { heid beperkt wordt bij het } \\
\text { traplopen? }\end{array}$ & 6 & Varieert & $x$ & $x$ \\
\hline
\end{tabular}

In de analyses bekeken we of de interventie- en controlegroep vergelijkbaar waren op achtergrondkenmerken, de mate van acculturatie en de baselinewaarden van de uitkomstmaten op T0. Dit deden we met een t-toets voor de continue variabelen (leeftijd en schaalscores LAS) en met een chi-kwadraattoets voor de categoriale variabelen. Vervolgens berekenden we verschilscores op de uitkomstmaten en bekeken we met een t-toets of de verschilscores tussen de interventiegroep en controlegroep verschilden.

\section{Kwalitatief onderzoek}

$\mathrm{Na}$ afloop van het onderzoek hebben we enkele patiënten en de poh's-ggz in de interventiegroep gevraagd naar hun ervaringen met het BCI. In de interviews met de poh's-ggz zijn de volgende onderwerpen besproken: ervaringen met het toepassen van het BCI, de geschiktheid van de hulpmiddelen (vragenlijst-BCI en kaartje met verkorte versie op A5-formaat), en de invloed van het BCI op de klachtverheldering, het verloop van de behandeling en de behandelaar-cliëntrelatie. De patiënten vroegen we in het interview naar hun ervaringen met de gesprekken met de pohggz in het algemeen en de toepassing van het BCI in het bijzonder.

\section{Resultaten}

\section{Deelnemers}

We hebben 87 patiënten geïncludeerd in het onderzoek (52 in de interventiegroep en 35 in de controlegroep). Van 46 patiënten hebben we de gegevens van zowel het startinterview als het vervolginterview (31 in de interventiegroep en vijftien in de controlegroep). De resultaten zijn gebaseerd op de antwoorden van deze 46 patiënten. Zie fig. 1 voor de inclusie en uitstroom van patiënten.

De deelnemers waren gemiddeld 41 jaar oud (variërend tussen achttien en 78 jaar; zie tab. 2). Er deden meer vrouwen $(65 \%)$ dan mannen mee. Bijna de helft (43\%) was van Surinaamse afkomst; $15 \%$ had een Marokkaanse achtergrond, $15 \%$ een Turkse en $26 \%$ een andere niet-westerse achtergrond. Driekwart gaf aan religieus te zijn; $39 \%$ was moslim, $24 \%$ christen en $9 \%$ Hindoestaan. Bijna de helft van de deelnemers was niet/nooit getrouwd en bijna een kwart was getrouwd. Bijna driekwart van de deelnemers had een middelhoge opleiding (lager beroepsonderwijs tot en met vwo). Ruim een derde moest schulden maken of hun spaargeld aanspreken om rond te kunnen komen.

We vonden geen significante verschillen tussen de deelnemers in de interventie- en controlegroep op de meeste achtergrondkenmerken en de mate van acculturatie. Alleen voor de financiële situatie was 
Figuur 1 Stroomdiagram van inclusie van patiënten

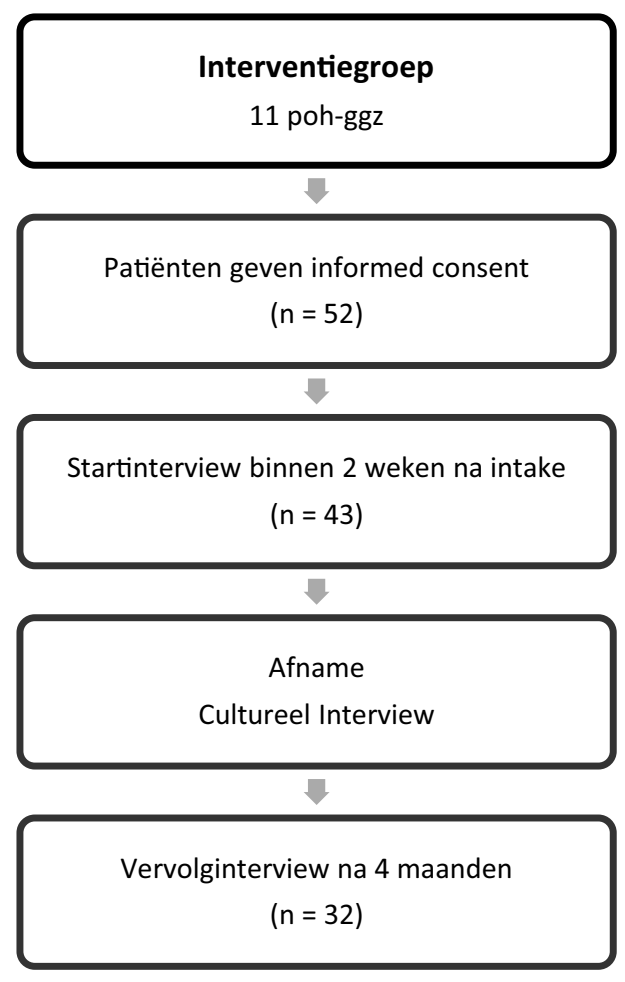

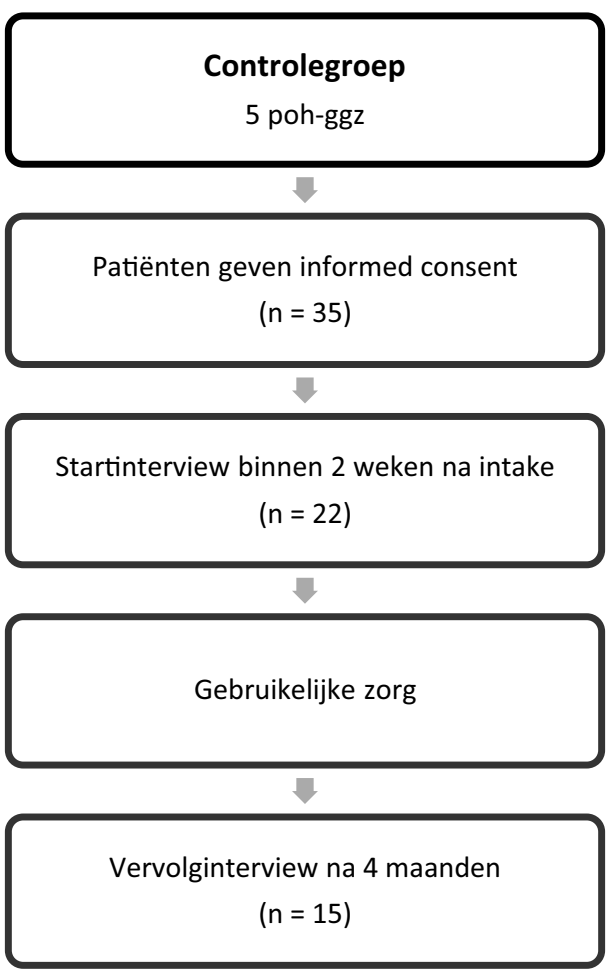

er een verschil (chi-kwadraat $=10,42 ; p=0,034$ ). In de interventiegroep zaten meer deelnemers die precies konden rondkomen en in de controlegroep zaten meer deelnemers die een beetje geld overhielden. We hebben de groep waarvan de gegevens van beide meetmomenten beschikbaar waren (interventie- en controlegroep samen) vergeleken met de groep waarvan alleen baselinegegevens beschikbaar waren, zogenaamde uitvallers. Ook hier vonden we alleen een significant verschil voor de financiële situatie (chikwadraat $=11,10 ; p=0,025)$. In de groep met uitvallers zaten meer deelnemers die geld overhielden.

\section{Uitkomstmaten}

De interventie- en controlegroep verschilden niet significant van elkaar wat betreft de baselinewaarden en de verandering in waardering van de patiënt-zorgverlenerrelatie, vertrouwen in artsen en gevoel van controle (zie tab. 3). Zowel de ervaren fysieke als ervaren psychische gezondheid verbeterden over de tijd, waarbij de verbetering het grootst was voor de psychische gezondheid. De beide groepen verschilden daarin niet significant van elkaar. Niet alle huisartsinformatiesystemen waren volledig beschikbaar, waardoor verschillen in therapietrouw niet konden worden gerapporteerd.

\section{Interviews met de patiënten}

\section{Ervaringen met het $\mathrm{BCl}$}

We interviewden vier patiënten uit de interventiegroep en vijf patiënten uit de controlegroep. Beide groepen waren over het algemeen positief over de gesprekken met de poh-ggz. Ze hadden de gesprekken ervaren als een open gesprek waarin ze alles konden vertellen en de poh-ggz gaf bruikbare adviezen: 'Hij laat je uitpraten, hij laat je je zegje doen, hij geeft adviezen.' (controle)

Het bleek lastig om te bepalen of het BCI volledig was toegepast. De eerste gesprekken met de poh-ggz waren voor de patiënten al enkele maanden geleden. Hierdoor wisten ze niet meer precies wat er besproken was en hoe uitvoerig dat was gebeurd. Patiënten uit beide groepen gaven aan dat achtergrond, religie en de thuissituatie aan bod waren gekomen. Ook gaven enkele patiënten in de interventiegroep aan dat onderdelen van het BCI niet aan bod waren geweest.

Over het bespreken van de familiesituatie: '... hebben we het eigenlijk helemaal niet zo over gehad. (...) Maar ik heb denk ik daar zelf ook wel heel erg de boot afgekapt.' (interventie)

\section{Meerwaarde van het $\mathrm{BCl}$}

De geïnterviewde patiënten gaven aan het over het algemeen prima te vinden om te praten over hun culturele achtergrond. Patiënten in beide groepen meenden dat het voor de poh-ggz belangrijk is om inzicht te hebben in de persoonlijke situatie en achtergrond, maar dat de relevantie afhangt van het individu en de situatie. Ze vonden het vooral relevant voor anderen: 'Het is een multiculturele samenleving (...) alles te maken met thuis ... cultuurgebonden. Dus voor hem [de poh] is ook belangrijk om te weten hoe de leefsituatie thuis is.' (controle) 


\section{Wetenschappelijk artikel}

Tabel 2 Beschrijving van de achtergrondkenmerken van de deelnemers

\begin{tabular}{|c|c|c|c|c|}
\hline & $\begin{array}{l}\text { Interventiegroep } \\
(n=31)\end{array}$ & $\begin{array}{l}\text { Controlegroep } \\
(n=15)\end{array}$ & $\begin{array}{l}\text { Totaal } \\
(n=46)\end{array}$ & $p$-waarde \\
\hline Leeftijd (gemiddelde; standaarddeviatie) & $40,8(2,5)$ & $42,3(3,0)$ & $41,3(13,0)$ & 0,712 \\
\hline \multicolumn{5}{|l|}{ Geslacht (aantal, percentage) } \\
\hline $\operatorname{man}$ & $11(35 \%)$ & $5(33 \%)$ & $16(35 \%)$ & \multirow[t]{2}{*}{0,886} \\
\hline vrouw & $20(65 \%)$ & $10(67 \%)$ & $30(65 \%)$ & \\
\hline \multicolumn{5}{|l|}{ Etniciteit (aantal, percentage) } \\
\hline Surinaams & $11(35 \%)$ & $9(60 \%)$ & $20(43 \%)$ & \multirow[t]{4}{*}{0,316} \\
\hline Marokkaans & $6(19 \%)$ & $1(7 \%)$ & $7(15 \%)$ & \\
\hline Turks & $6(19 \%)$ & $1(7 \%)$ & $7(15 \%)$ & \\
\hline Anders & $8(26 \%)$ & $4(27 \%)$ & $12(26 \%)$ & \\
\hline \multicolumn{5}{|l|}{ Religie (aantal, percentage) } \\
\hline geen & $7(23 \%)$ & $4(27 \%)$ & $11(24 \%)$ & \multirow[t]{5}{*}{0,125} \\
\hline Islamitisch & $15(48 \%)$ & $3(20 \%)$ & $18(39 \%)$ & \\
\hline christelijk & $6(19 \%)$ & $5(33 \%)$ & $11(24 \%)$ & \\
\hline hindoeïstisch & $3(10 \%)$ & $1(7 \%)$ & $4(9 \%)$ & \\
\hline anders & $0(0 \%)$ & $2(13 \%)$ & $2(4 \%)$ & \\
\hline \multicolumn{5}{|l|}{ Burgerlijke staat (aantal, percentage) } \\
\hline nooit gehuwd geweest & $13(42 \%)$ & $9(60 \%)$ & $22(48 \%)$ & \multirow[t]{5}{*}{0,664} \\
\hline gehuwd & $8(26 \%)$ & $3(20 \%)$ & $11(24 \%)$ & \\
\hline gescheiden van tafel en bed & $0(0 \%)$ & $0(0 \%)$ & $0(0 \%)$ & \\
\hline voor de wet gescheiden & $5(16 \%)$ & $2(13 \%)$ & $7(15 \%)$ & \\
\hline weduwe/weduwnaar & $5(16 \%)$ & $1(7 \%)$ & $6(13 \%)$ & \\
\hline \multicolumn{5}{|l|}{ Opleidingsniveau (aantal, percentage) ${ }^{a}$} \\
\hline laag & $6(19 \%)$ & $1(7 \%)$ & $7(15 \%)$ & \multirow[t]{3}{*}{0,527} \\
\hline midden & $21(68 \%)$ & $12(80 \%)$ & $33(72 \%)$ & \\
\hline hoog & $4(13 \%)$ & $2(13 \%)$ & $6(13 \%)$ & \\
\hline \multicolumn{5}{|l|}{ Financiële situatie (aantal, percentage) } \\
\hline moet schulden maken & $6(19 \%)$ & $4(29 \%)$ & $10(22 \%)$ & \multirow[t]{5}{*}{0,034} \\
\hline moet spaarmiddelen enigszins aanspreken & $5(16 \%)$ & $1(7 \%)$ & $6(13 \%)$ & \\
\hline kan precies rondkomen & $16(52 \%)$ & $2(15 \%)$ & $18(40 \%)$ & \\
\hline kan een beetje geld overhouden & $4(13 \%)$ & $6(43 \%)$ & $10(22 \%)$ & \\
\hline kan veel geld overhouden & $0(0 \%)$ & $1(7 \%)$ & $1(2 \%)$ & \\
\hline \multicolumn{5}{|c|}{ Mate van acculturatie (gemiddelde; standaarddeviatie) } \\
\hline vaardigheden & $10,0(1,0)$ & $9,3(1,1)$ & $9,8(5,1)$ & 0,687 \\
\hline tradities & $17,2(0,9)$ & $14,3(1,1)$ & $16,3(4,7)$ & 0,053 \\
\hline sociale integratie & $16,5(0,7)$ & $17,6(1,1)$ & $16,8(3,9)$ & 0,354 \\
\hline waarden en normen & $16,3(0,7)$ & $17,5(1,1)$ & $16,8(3,8)$ & 0,326 \\
\hline verlies & $25,0(1,2)$ & $20,9(2,5)$ & $23,7(8,0)$ & 0,111 \\
\hline
\end{tabular}

a Opleidingsniveau is ingedeeld in de volgende categorieën: laag niet naar school geweest tot en met lagere schaal; midden lager beroepsonderwijs tot en met vwo; hoog hoger beroepsonderwijs en universiteit

'Het hangt er wel vanaf wie je tegenover je hebt zitten. Wil die persoon het daar wél over hebben?' (interventie)

'Ik wilde daar [probleem] aan werken, en daar wilde ik het ook bij houden.' (interventie)

\section{Interviews met de poh's-ggz}

Van de elf poh's-ggz uit de interventiegroep namen er zeven deel aan een interview en één poh heeft de vragen schriftelijk beantwoord. Twee poh's-ggz konden niet deelnemen en één was met zwangerschapsverlof.

\section{Ervaringen met het gebruik van het $\mathrm{BCl}$}

Uit de vraag hoe het BCI was toegepast blijkt dat de meeste poh's-ggz zelf beoordeelden welke onderdelen uit het BCI op dat moment in het gesprek bruikbaar waren. De lijst werd niet chronologisch afgenomen en ook niet altijd in zijn geheel. De poh's-ggz verdeelden onderdelen uit het BCI over meerdere gesprekken. Van de hulpmiddelen werd de uitgebreide vragenlijst met instructies nauwelijks gebruikt. Het verkorte handzame A5-formaat vonden de poh's-ggz wel bruikbaar. Extra materialen zijn volgens de poh'sggz niet nodig, maar training en intervisie zijn wel 
Tabel 3 Gemiddelde score (standaarddeviatie) op uitkomstmaten twee weken na intake (startinterview; t0) en vier maanden later (vervolginterview; $\mathrm{t} 1$ ), verschillen in verschilscore getoetst met t-toets

\begin{tabular}{|c|c|c|c|c|c|c|c|}
\hline \multirow[t]{2}{*}{ Uitkomstmaat } & \multicolumn{3}{|c|}{ Interventiegroep $(n=31)$} & \multicolumn{3}{|c|}{ Controlegroep $(n=15)$} & \multirow{2}{*}{$\begin{array}{l}P \text {-waarde verschil- } \\
\text { score }\end{array}$} \\
\hline & to & $\mathrm{t} 1$ & Verschil & to & $\mathrm{t} 1$ & Verschil & \\
\hline $\begin{array}{l}\text { Waardering patiënt-zorgverlenersre- } \\
\text { latie }\end{array}$ & $\begin{array}{l}96,9 \\
(9,6)\end{array}$ & $\begin{array}{l}94,1 \\
(13,8)\end{array}$ & $\begin{array}{l}-2,9 \\
(15,7)\end{array}$ & $\begin{array}{l}93,9 \\
(9,3)\end{array}$ & $\begin{array}{l}94,1 \\
(8,3)\end{array}$ & $\begin{array}{r}1,6 \\
(1,4)\end{array}$ & 0,324 \\
\hline Vertrouwen in artsen & $\begin{array}{r}3,6 \\
(0,9)\end{array}$ & $\begin{array}{r}3,5 \\
(0,9)\end{array}$ & $\begin{array}{l}-0,2 \\
(0,11)\end{array}$ & $\begin{array}{r}3,2 \\
(0,8)\end{array}$ & $\begin{array}{r}3,3 \\
(0,7)\end{array}$ & $\begin{array}{r}0,1 \\
(0,2)\end{array}$ & 0,300 \\
\hline Gevoel van controle & $\begin{array}{l}10,5 \\
(6,0)\end{array}$ & $\begin{array}{l}10,7 \\
(4,9)\end{array}$ & $\begin{array}{r}0,2 \\
(1,1)\end{array}$ & $\begin{array}{l}11,7 \\
(4,2)\end{array}$ & $\begin{array}{l}11,3 \\
(4,2)\end{array}$ & $\begin{array}{l}-0,3 \\
(1,0)\end{array}$ & 0,772 \\
\hline Ervaren lichamelijke gezondheid & $\begin{array}{l}45 \\
(22,83)\end{array}$ & $\begin{array}{l}50,2 \\
(26,34)\end{array}$ & $\begin{array}{c}5,4 \\
(3,36)\end{array}$ & $\begin{array}{l}50,8 \\
(28,63)\end{array}$ & $\begin{array}{l}54,2 \\
(24,40)\end{array}$ & $\begin{array}{c}3,3 \\
(6,48)\end{array}$ & 0,753 \\
\hline Ervaren psychische gezondheid & $\begin{array}{l}36,6 \\
(18,00)\end{array}$ & $\begin{array}{l}49,3 \\
(24,47)\end{array}$ & $\begin{array}{l}13,1 \\
(4,18)\end{array}$ & $\begin{array}{l}35,3 \\
(18,07)\end{array}$ & $\begin{array}{l}50,4 \\
(21,59)\end{array}$ & $\begin{array}{l}13,6 \\
(6,00)\end{array}$ & 0,948 \\
\hline
\end{tabular}

belangrijk: 'Het zou ook fijn zijn om ervaringen en tips van anderen te bundelen en te verspreiden. Met name over de vraag: hoe begin je? Hoe pak je het aan?'

Enkele poh's-ggz hadden de ervaring dat het woord 'cultuur' patiënten kon afschrikken of afstand kon scheppen. Zij vermeden dat woord liever in de introductie. Ze stelden dan een vraag als de volgende: 'Ik ben benieuwd hoe je geworden bent wie je bent.' De ervaring is dat mensen het fijn vinden om daarover te vertellen en bij het verleden stil te staan. Veel van hen vertellen graag over het land van herkomst.

Tijdsdruk was een belangrijke belemmering voor het gebruik van het BCI. Mensen komen bij de pohggz met concrete klachten en willen snel toewerken naar klachtvermindering. Poh's-ggz hebben per consult maar beperkte tijd. Om grote delen van die tijd te besteden aan het uitvragen van informatie beschouwden sommige poh's-ggz als tijdverlies.

\section{Meerwaarde van het $\mathrm{BCl}$}

Een aantal poh's-ggz gaf aan dat het BCI stimuleert om de context beter te exploreren. De vragen helpen om verder te onderzoeken en niet te snel aan te nemen dat de poh-ggz wel weet hoe het in elkaar steekt. Daarbij zeiden meerdere poh's-ggz dat dit niet alleen bruikbaar is bij patiënten met een migrantenachtergrond, maar bij iedereen. Als voorbeeld noemden ze dat het verschil tussen stad en platteland soms groter is dan dat tussen Nederland en het land van herkomst.

De poh's-ggz hechtten belang aan het onderdeel 'Culturele identiteit', vooral voor klachtenverheldering. Bijna alle poh's-ggz vonden taal daarbij belangrijk. Ze gaven aan dat mensen die de Nederlandse taal beperkt beheersen, waarschijnlijk hun klachten onvoldoende kunnen verwoorden. De poh's-ggz vonden het ook belangrijk om te achterhalen of er binnen een gezin taalverschillen zijn. Vragen naar etnische achtergrond is belangrijk, omdat er veel verschillen zijn tussen bijvoorbeeld Turkse groepen (qua religie, regio van herkomst).

De vragen onder 'Culturele factoren in de psychosociale omgeving' gaven de poh's-ggz aanknopings- punten voor de behandeling. Vragen naar kracht- en stressbronnen, en steun vanuit de omgeving boden de poh's-ggz meer inzicht in de invloed van sommige gebeurtenissen of de relaties in het leven van de patiënt. Dit gaf zicht op mogelijkheden om de veerkracht te versterken.

De meerwaarde van de andere onderdelen 'Culturele definitie en verklaringen' en 'Culturele elementen tussen cliënt en hulpverlener' kwam in de interviews minder duidelijk naar voren. De ervaringen die de poh's-ggz hiermee hadden wisselden sterk per patiënt: soms kwam hier weinig uit, andere keren leverde het juist nieuwe inzichten op.

De meeste poh's-ggz vonden dat het gebruik van het BCI bijdroeg aan de therapeutische relatie. Ze gaven aan dat hoe dichter ze bij een patiënt staan, hoe beter ze kunnen aansluiten op diens belevingswereld. En dat dat belangrijk is voor een effectieve behandeling: 'Het leert je van de klachten af te stappen en om de cliënt te versterken, te empoweren.'

'Je leert een andere dimensie van iemand kennen, je komt dichter bij iemands identiteit.'

'Je krijgt een betere band, mensen voelen zich beter gehoord en gezien.'

\section{Beschouwing}

In het huidig onderzoek keken we naar de mogelijke effecten van en de ervaringen met het BCI in de huisartsenpraktijk. Het BCI is door de poh's-ggz afgenomen bij niet-westerse migranten die met psychische klachten bij de huisarts kwamen. We vonden geen verschillen tussen de interventie- en controlegroep wat betreft veranderingen in waardering van de patiënt-zorgverlenerrelatie, vertrouwen in artsen, gevoel van controle of fysieke en psychische gezondheid. Dit komt mede door het beperkte aantal geïncludeerde patiënten en de aanzienlijke uitval. De uitval lijkt bij bepaalde vormen van zorg groter te zijn bij patiënten met een niet-westerse achtergrond [27]. 
Een belangrijk resultaat is dat de instroom van patiënten in het onderzoek door meerdere factoren tegenviel. Er waren weinig nieuwe intakes in de onderzoeksperiode door reorganisaties binnen de ggz. Daarnaast vonden sommige poh-ggz het lastig om patiënten direct aan het begin van het eerste gesprek te vragen om deel te nemen. Op dat moment staan patiënten volgens hen niet open voor een onderzoek en konden ze moeilijk inschatten of de patiënt een geschikte deelnemer was. Ook kwamen volgens de poh's-ggz veel patiënten niet in aanmerking voor het onderzoek. Bijvoorbeeld omdat de problematiek van de patiënt te zwaar was, omdat er sprake was van een taalbarrière (vooral bij laag opgeleiden) of omdat de poh-ggz inschatte dat de culturele achtergrond niet relevant was (vooral bij hoog opgeleiden). Deze redenen werden ook aangegeven door de poh die geen enkele patiënt includeerden. Dit heeft geleid tot een selectiebias, waardoor mogelijk een groep is uitgesloten die baat zou hebben van het BCI. Een beperking van dit onderzoek is dat de poh's de redenen waarom ze patiënten niet uitnodigden, niet hebben vastgelegd, waardoor er geen zicht is op de volledige bronpopulatie. In toekomstig onderzoek moet de inclusie van deelnemers minder afhankelijk worden van de persoonlijke inschatting van de poh.

De kwalitatieve data leverden inzichten op over de toepasbaarheid van en ervaringen met het BCI. De poh's-ggz gaven na afloop aan dat ze het BCI een waardevol instrument vonden. Het geeft concrete handvatten voor het stellen van vragen over de culturele achtergrond en geeft meer inzicht in de leefwereld en migratiegeschiedenis. Dit komt overeen met eerdere positieve ervaringen van zorgverleners [11, 15, 17, 18]. De meeste poh's-ggz namen niet het gehele BCI af, maar stelden veel meer de vragen die ze op dat moment relevant achtten. Dit is eigen aan het gebruik van deze tool, maar maakt het wel lastiger om de effecten ervan te evalueren. Het is geen standaard meetinstrument, maar een lijst met open vragen. Ook verspreidden de poh's de vragen liever over meerdere gesprekken. Ze vonden vooral de onderdelen 'Culturele identiteit' en 'Culturele factoren in de sociale omgeving' relevant. Ook in het onderzoek van Groen en collega's vonden zorgverleners het onderdeel 'Culturele identiteit' belangrijker dan het onderdeel 'Culturele definities en verklaringen' [11].

Uit de gesprekken met de poh's-ggz en patiënten kwamen enkele belemmeringen voor het gebruik van het BCI naar voren. De poh's-ggz noemden vooral het gebrek aan tijd. Enkele poh's-ggz gaven aan dat ze hun tijd liever besteden aan het bespreken van de klachten en manieren om daarmee om te gaan. Het idee achter het BCI is echter dat het op termijn resulteert in tijdwinst doordat de klachten sneller verholpen worden. Patiënten vonden het geen probleem om hun culturele achtergrond te bespreken en zagen het mogelijke nut van de toepassing van het BCI. Wel gaven ze aan dat de relevantie van de vragen afhangt van het individu en de situatie.

Een andere beperking van het onderzoek was de korte follow-upperiode. Een periode van vier maanden is mogelijk te kort om de effecten van het BCI te kunnen aantonen. Verder zijn in dit artikel eerder geplande uitkomsten, zoals therapietrouw na zes maanden en gebruikte zorg, niet meegenomen vanwege deze korte follow-up en onvolledige registratie. Daarnaast werkten alle poh's-ggz in een cultuurdiverse huisartsenpraktijk en waren ze bekend met het concept 'cultuursensitieve zorg'. Uit de interviews met de patiënten bleek dat ook de poh's-ggz in de controlegroep vragen hadden gesteld over de culturele achtergrond. Dit lijkt ons eerder een gevolg van het reeds bestaande niveau van culturele competentie, dan van contaminatie tussen verschillende poh's binnen een gezondheidscentrum. Een belangrijke vraag is dan ook wat het verschil is geweest tussen de poh's-ggz in de interventie- en controlegroep, wat het extra moeilijk maakte om de meerwaarde van het BCI aan te tonen. Om hier zicht op te krijgen zouden de gesprekken in een vervolgonderzoek kunnen worden opgenomen.

\section{Aanbevelingen}

Het onderzoek heeft kennis opgeleverd over het gebruik van het BCI door de poh's-ggz en komt overeen met wat reeds in de literatuur bekend is. De variatie in uitvoering ervan is groot en daarom is het ingewikkeld om het effect door middel van een trial aan te tonen. Het huidige onderzoek geeft aanleiding om enkele kernvragen aan te wijzen, waarbij de rest dient als voorbeelden voor doorvragen [11]. Het idee achter de OCF in de DSM is om de eigen interpretatie van de patiënt van zijn/haar klachten te achterhalen (etnografie) en niet om als checklist van factoren te dienen [12]. Het BCI moet dan ook niet gezien worden als een instrument waarvan altijd alle vragen in dezelfde volgorde gesteld moeten worden. Dit sluit aan bij de manier waarop de poh's-ggz het BCI hebben toegepast.

Op basis van de kwalitatieve data is het BCI aangepast en beter toegesneden op de praktijk van de pohggz. Het kan als hulpmiddel worden ingezet voor het bevorderen van het cultuursensitief handelen van de poh-ggz in het bijzonder en zorgverleners in het algemeen. Via Pharos is een trainingspakket voor het gebruik van het BCI verkrijgbaar.

Dankbetuiging Het onderzoek werd gefinancierd door ZonMw, binnen het programma Winst door Verschil (nr. 41710005). We willen de volgende personen bedanken voor hun bijdrage: Jitske de Vries, die het merendeel van het project heeft uitgevoerd, en de deelnemende huisartsenpraktijken, poh's-ggz, patiënten en interviewers. Ook willen we de leden van de begeleidingscommissie van het project danken voor hun inbreng. Naast de auteurs waren dit: R. van Dijk (Indigo Zorgservice), S. Groen (GGZ Drenthe), H. Rohlof (Centrum 
'45), G. Tempelman (Zorggroep Almere), prof.dr. M. van Tulder (VU) en prof.dr. P. Verhaak (NIVEL).

Open Access This article is licensed under a Creative Commons Attribution 4.0 International License, which permits use, sharing, adaptation, distribution and reproduction in any medium or format, as long as you give appropriate credit to the original author(s) and the source, provide a link to the Creative Commons licence, and indicate if changes were made. The images or other third party material in this article are included in the article's Creative Commons licence, unless indicated otherwise in a credit line to the material. If material is not included in the article's Creative Commons licence and your intended use is not permitted by statutory regulation or exceeds the permitted use, you will need to obtain permission directly from the copyright holder. To view a copy of this licence, visit http://creativecommons.org/licenses/by/4.0/.

\section{Literatuur}

1. Fassaert T, De Wit MA, Verhoeff AP, Tuinebreijer WC, Gorissen WH, Beekman AT, et al. Uptake of health services for common mental disorders by first-generation Turkish and Moroccan migrants in the Netherlands. BMCPublic Health. 2009;9:307.

2. Nielen M, Verheij R, Bakker D, Devillé WL. Vooronderzoek verbetering kwaliteit huisartsenzorg in achterstandsgebieden grote steden. Utrecht: NIVEL; 2007.

3. Landelijke stuurgroep Multidisciplinaire richtlijnontwikkeling in de GGZ. GGZ-richtlijnen. Utrecht: Trimbosinstituut; 2005. Beschikbaar via: www.ggzrichtlijnen.nl.

4. Bhui K, Stansfeld S, Hull S, Priebe S, Mole F, Feder G. Ethnic variations in pathways to and use of specialist mental health services in the UK. Systematic review. Br J Psychiatry. 2003;182:105-16.

5. Briones DF, Heller PL, Chalfant HP, Roberts AE, AguirreHauchbaum SF, FarrWFJr. Socioeconomic status, ethnicity, psychological distress, and readiness to utilize a mental health facility. Am J Psychiatry. 1990;147(10):1333-40.

6. Leong FTL, Wagner NS, Tata SP. Racial and ethnic variations in help-seeking attitudes. In: Ponterotto JG, Casas JM, SuzukiLA, AlexanderCM, redactie. Handbook of multicultural counselling. Thousand Oaks: SAGE; 1995:415-38.

7. Razali SM, Najib MA. Help-seeking pathways among Malay psychiatric patients. Int JSoc Psychiatry. 2000;46(4):281-9.

8. Beach MC, Gary TL, Price EG, Robinson K, Gozu A, Palacio A, et al. Improving health care quality for racial/ethnic minorities: a systematic review of the best evidence regarding provider and organization interventions. BMC Public Health. 2006;6:104.

9. Chips JA, Simpson B, Brysiewicz P. The effectiveness of cultural-competence training for health professionals in community-based rehabilitation: a systematic review of literature. Worldviews Evid Based Nurs. 2008;2:85-94.

10. Henningsen P, Zipfel S, Herzog W. Management of functional somatic syndromes. Lancet. 2007;369(9565):946-55.
11. Groen SP, Richters A, Laban CJ, DevilléWL. Implementation of the cultural formulation through a newly developed brief cultural interview: pilot data from the Netherlands. Transcult Psychiatry. 2017;54(1):3-22.

12. Lewis-Fernandez R, Aggarwal NK, Baarnhielm S, Rohlof H, Kirmayer LJ, Weiss MG, et al. Culture and psychiatric evaluation: operationalizing cultural formulation for DSM-5. Psychiatry. 2014;77(2):130-54.

13. Cuéllar I, Paniagua FA. Handbook of multicultural mental health: assessment and treatment of diverse populations. Orlando: Academic Press; 2000.

14. Borra R, Van Dijk R, Rohlof H. Cultuur, classificatie en diagnose. Cultuursensitief werken met de DMS-IV. Houten: Bohn Stafleu van Loghum; 2002.

15. Beijers H, Tempelman G. Cultureel interview overbrugt cultuurverschillen. Phaxx. 2009;1:10-3.

16. GroenS. Beknopteversievanhet cultureleinterview. Beilen: DeEvenaar; 2006.

17. Pinksen B. Het gebruik van het cultureel interview in het veld. Groningen: Pharos; 2010.

18. Starmans R. De waarde van het culturele interview in een huisartspraktijk. Utrecht: Universiteit van Utrecht; 2005.

19. Seeleman C, Hermans J, Lamkaddem M, Suurmond J, Stronks K, Essink-Bot ML. A students' survey of cultural competence as a basis for identifying gaps in the medical curriculum. BMCMed Educ. 2014;14:216.

20. Mooren TTM, Knipscheer JW, Kamperman AN, Kleber RJ, Komproe IH. The Lowlands Acculturation Scale: validity of and adaptation measure among migrants in the Netherlands. In: Mooren TTM, redactie. The impact of war studies on the psychological consequences of war and migration. Delft: Eburon; 2001. pag. 49-69.

21. Luborsky L, Barber JP, Siqueland L, Johnson S, Najavits LM, Frank A, et al. The Revised Helping Alliance Questionnaire (HAq-II): psychometric properties. J Psychother Pract Res. 1996;5(3):260-71.

22. Trijsburg RW, Van't Spijker A, Van Dam QD, Duivenvoorden HJ. De Helping Alliance Questionnaire (HAQ-II). Tijdschr Psychother. 1999;25(3):56-65.

23. DuganE, TrachtenbergF, Hall MA. Development of abbreviated measures to assess patient trust in a physician, a health insurer, and the medical profession. BMC Health Serv Res. 2005;5:64

24. Pearlin LI, Schooler C. The structure of coping. J Health Soc Behav. 1978;19(1):2-21.

25. Gadalla TM. Sense of mastery, social support, and health in elderly Canadians. J Aging Health. 2009;21(4):581-95.

26. Ware JJr, Kosinski M, Keller SD. A 12-item short-form health survey: construction of scales and preliminary tests of reliability and validity. Med Care. 1996;34(3):220-33.

27. Sloots M, Scheppers EF, Van de Weg FB, Dekker JH, Bartels EA, Geertzen JH, et al. Higher dropout rate in nonnative patients than in native patients in rehabilitation in the Netherlands. Int J Rehabil Res. 2009;32(3):232-7. 